\title{
HUMAN COMFORT IN ARTIFICIAL PLACE
}

DOI: 10.18485/arh_pt.2020.7.ch51

\section{_ Ramos Gonzalez, Nicolas}

University of Pécs, Faculty of Engineering and Information Technology, Marcell Breuer Doctoral School, 2 Boszorkány Street, 7624 Pécs,

Hungary, nicolasramosgonzalez@gmail.com

\section{_ Medvegy Gabriella}

University of Pécs, Faculty of Engineering and Information Technology,

2 Boszorkány Street, 7624 Pécs, Hungary, medvegygabriella@mik.pte.hu

\section{Borsos Ágnes}

University of Pécs, Faculty of Engineering and Information Technology,

2 Boszorkány Street, 7624 Pécs, Hungary, agnesborsos@mik.pte.hu

\section{Z Zoltán Erzsébet Szeréna}

University of Pécs, Faculty of Engineering and Information Technology,

2 Boszorkány Street, 7624 Pécs, Hungary, betty.zoltan@pmmik.pte.hu

\section{_ Gazdag Gábor}

University of Pécs, Faculty of Engineering and Information Technology,

2 Boszorkány Street, 7624 Pécs, Hungary, gabor.gazdag95@gmail.com

\section{_ Noori Pooya \\ University of Pécs, Faculty of Engineering and Information Technology, 2 Boszorkány Street, 7624 Pécs, Hungary, pooya1652@gmail.com}

\begin{abstract}
Since prehistoric times humans have adapted and modified their environment according to their necessities. Nowadays, technology has advanced to the point that we feel we are living in an artificial environment, and we have the sensation of being far away from a natural setting and feel uncomfortable. Especially, in our workplaces. Consequently, in which way can we develop a comfortable working space as humans and keep its efficiency? In addition, what are the elements that assure the well-being of the workers in an artificial interior space?

This paper is based on an investigation of a research group and will analyse a current example of an office building in Budapest, presenting the information recorded of thermal comfort, acoustics, lighting and air quality. It also includes the processed data from a survey conducted among three hundred employees of the company. The building was designed with an open office concept, which consists of two major areas: workstations and conference rooms. There are also some spaces originally dedicated to leisure activities, which are underused. As a result of this research, which has the aim to improve the well-being and comfort of the personnel, it will be considered for the redesign of these spaces to improve the mood and conditions of the employees. As it is proven that these alternative spaces can maximize collaboration and creativity.
\end{abstract}

KEYWORDS _ workplace, well-being, productivity 


\section{INTRODUCTION}

The aim of this investigation has been to examine the effects of interior working spaces in the humans' health and propose alternative solutions. It has previously been observed that the impacts of interior office spaces on well-being of employees is noteworthy. A significant analysis and discussion on the subject was presented by Croome (2006). The author emphasises the importance of the good architecture enriches human capacities.

Therefore, according to an existing collaboration between the Faculty and an IT Company Services which has its headquarters in Budapest, the research group had the opportunity to examine office workplaces to analyse the employees' physical conditions. And, it has been noted that in some interior spaces, which originally, they were conceived as lounges, are underused.

The methodological approach taken in this study is a mixed methodology based on a questionnaire (answered by approximately 200 employees), empirical data (from parametrized analysed) and the workshop method.

Consequently, the research team redesigned these underused spaces, their ideas and concepts will be presented in this paper.

\section{Background}

The company has specialized in a wide range of IT and telecommunication services. The firm focuses on innovation and the development of system integration. The building is located in Budapest, and the first impression of the group was that the employees were working in a comfortable atmosphere and they had access to everything that high technology could offer in an office building nowadays. However, after the architects began to examine and explore the facilities, they recognised that the comfort conditions were not as good as it had been expected. For example, it could be seen that nobody was using the leisure spaces and it is possible that the reason why was that some of them do not have comfortable furniture that invited the employees to enjoy the space. On the other hand, the lighting conditions were not appropriate for relaxation since they were too bright. Consequently, the group could immediately figure out that there were interesting opportunities in these spaces, and it was a perfect place for developing new ideas according to nowadays office space trends.

\section{DESIGN METHODS}

There are three main types of study design used to identify the current functional situation of the space. To begin this process, the group elaborated a questionnaire which was presented in Hungarian and English and it answered by almost 200 employees. The design of the questionnaire was based on how the employees are satisfied of the characteristics of the physical environment. Then, the participants were asked to provide feedback on how they feel in the office. The benefit of this approach is that it could be possible to identify each personal opinion. Because, the survey was anonymous, so the surveyed had not to be concerned about expressing honestly their point of view. Second method used to identify the physical parameters involved was the data collection. After several deliberations with the representatives of the firm the group decided to take a floor as example of the global situation. In consequence, the third floor was chosen as a reference for doing the measurements. And within the floor it was specified different point for their analysis. Then acoustics, lighting, $\mathrm{CO} 2$ and thermal data were gathered from multiple points during the day. After collection, the samples were processed and organized for an appropriate understanding.

Once the samples were systematized and the questionnaire's answers processed the group was capable to understand the operation of the office. In order to address the possible solutions for the space, workshop meetings have placed. The studio was conducted over weeks and gave place for discussions and interchanging opinions. Following the conformational analysis of the site, it was necessary to divide the group in two. Through this process, the investigators emphasis the archi- 
tectural design exploring different theories and literature.

In addition, as a part of the subject "Interior Design" giving in Pollack Mihály Faculty of Engineering and Informational Technology of the University of Pécs, it was assigned the students the collaboration in the design development of these spaces.

The significant advantage of using a multidimensional approach is that allow the researchers to have different viewpoints or valid solutions for the same space. It allows the development of the ability of the creativity according the architectural requirements, well-being and information obtained from the measurements.

\section{RESULTS AND DISCUSSIONS}

After synthetizing the survey's data and analysing it is important to bearing in mind some relevant aspects. It can be seen that over thirty-six percent of those surveyed remarked the lack of private area for relaxation or have private meetings. Also, six percent highlighted that the existing lounges are not comfortable.

Some of the results obtained from the analysis of the questionnaire are shown in Figure 01 where it can be seen the positive and negative aspects remarked. Interestingly, the survey's results revealed that over thirty-five percent of the employees surveyed perceive the environment very noisy.

If, over eighty percent of respondents claim that they like the working atmosphere among the teams and they feel that they belong to a working community. However, perhaps unsurprisingly, they mentioned they would like to have private space for interaction.

In summary, these results show that the majority of the surveyed $(61 \%)$ would like to have more comfortable spaces for relaxation. That would allow them to have more opportunities for informal meetings and discussions. So, the group will take the challenging to design these spaces concerning employees' requirements, their well-being aspects and support virtual and telecommunications developing.
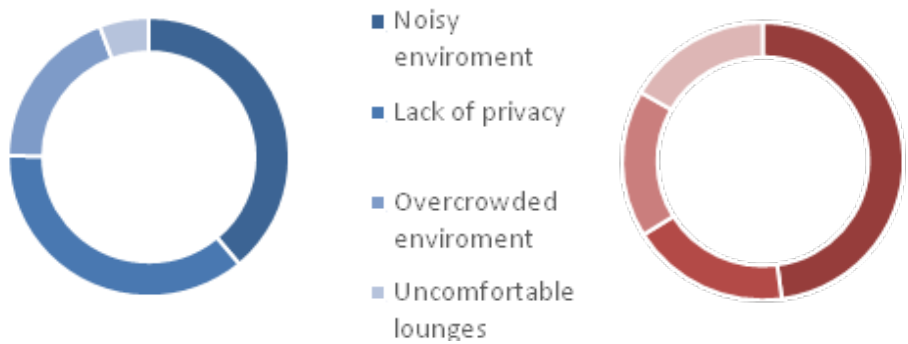

- Collegues

- Nice

enviroment

- Flexible shifts

Home office

_ Figure 1: Negative and positive aspects remarked within the questionnaire.

\section{LOUNGE DESIGNS}

\section{The functions}

The questionnaire's results, the sites evaluation and the new workspace trends [3] gave the group the idea of the functions that could be suitable to the interior spaces design. Then, concerning these aspects, it had been decided to give a wide variety of activities which allow the workers to relax, have privacy, have informal meetings, working-out and have video games-films hub space.

After several meetings and analyses of each lounge, the team decided to divide the spaces in two categories: lounges without windows and with windows. The spaces located in the inner space 
building, which do not have openings to the exterior, will be the space to focus and have private informal meetings. Meanwhile, the lounges with windows are bigger than the previous ones, it was unquestionable to provide them with other activities. The activities stipulated were decided according to the employees' needs, results reflected in the questionnaire's answers and there are mentioned in the previous paragraph.

The group divided the lounges among the members. And our sub-group will design three lounges.

\section{The Pine forest - 3rd floor - THE ALPINE VILLAGE}

Functions: focus room, private phone calls and private conversations

Size: 22 square meters.

Taking the floor's theme as a reference inspired by an Alpine little village located in the middle of the woods, comfortable "cottage" phone booths were designed for relaxation and private calls. The booths disposition in the space give the idea of a village and offer privacy but at the same time fluidity of the space. Please see figure 02 .

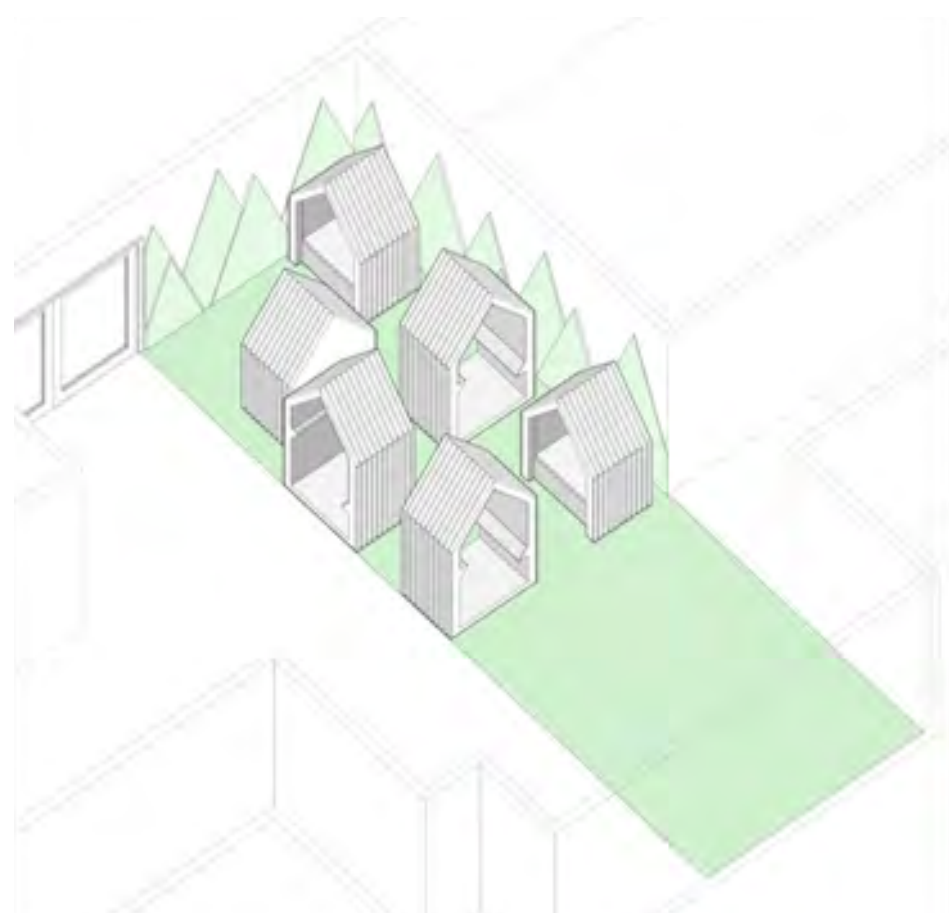

_ Figure 2: The cottage booths perspective - Image author: Gábor Gazdag

The booths are designed in the way that they can be assembled the parts without any tool, silently and with a couple of workers. The pieces are smaller and light. The pack is composed by the timber structure and plywood panels, the 3D printed plastic joints and upholstery. In the image 02 it can be appreciating the components and the ensemble's steps.

The idea is to encourage the employees to have a "workshop" day off to collaborate together in the construction of the booths.

Each "cottage" was built with a timber structure covered with plywood. This material is made from wood layers and they are bonded together. As it is well known, wood is a renewable resource, so plywood is an environmentally friendly product.

In addition, inside the booths, a comfortable and soft upholstery of polyurethane foam can be found, which gives a feeling of cosiness. In consequence, this finishing provides an excellent absorption of 
sounds and noises.

Technically speaking, the phone booths are provided with a cooling - heating system where each user can adjust the conditions according to their needs. This technical requirement gives much more comfort to users. All of the booths were designed with USB connection as well.

Last but not least, the brightness of illumination regarding every cottage can be controlled by each user within a light dimmer switch, according to their demands. Therefore, if employees want to read, they can choose a high light intensity.

According to the description below and the attached graphics, the main aim is to provide the maximum level of comfort. This idea is going to be presented through the resolution that the group gave considering the thermal, acoustic, lighting and well-being issues.

\section{Phone Booths (cottages):}
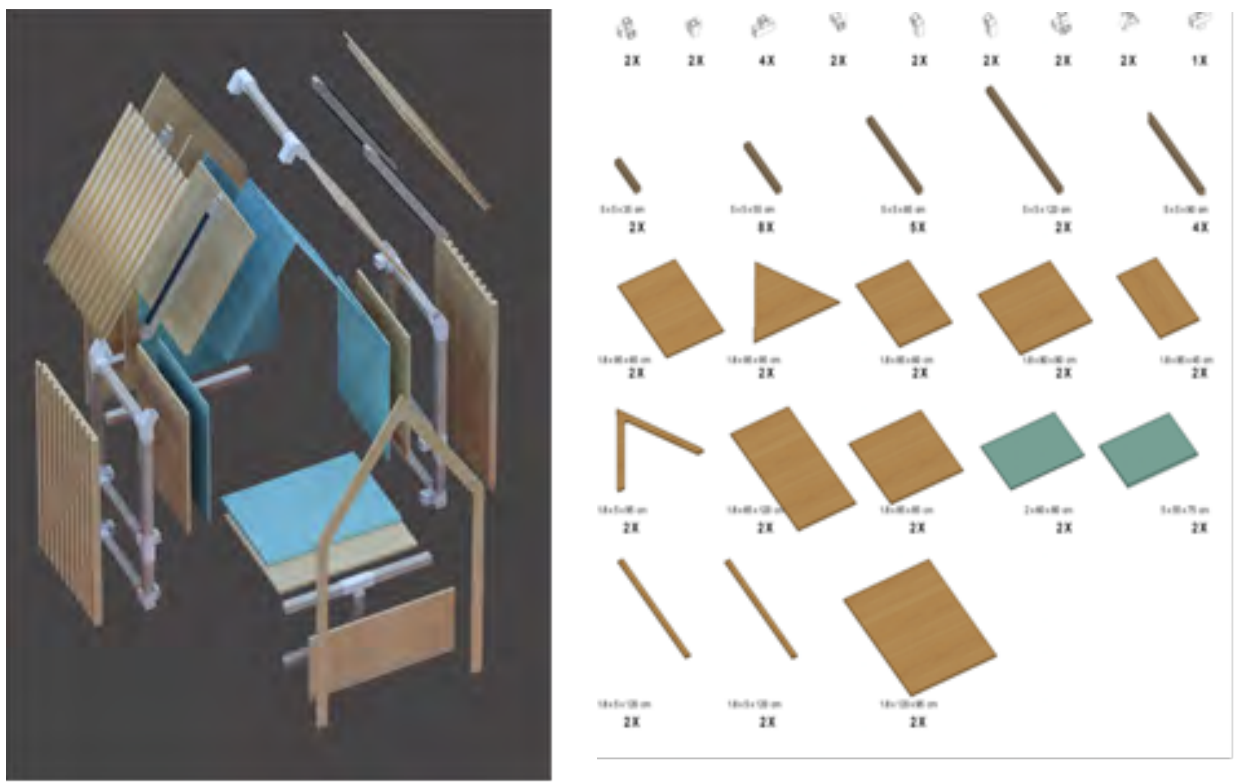

_ Figure 3: The parts to assemble a cottage booth-Image authors: Pooya Noora and Gábor Gazdag
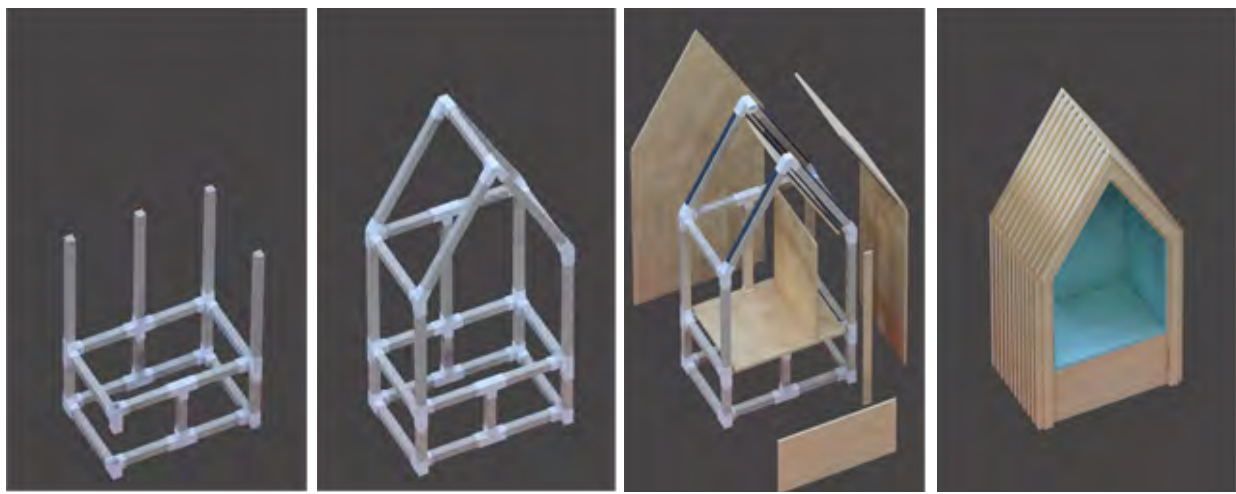

_ Figure 4: The steps to assemble a cottage booth - Image authors: Pooya Noora and Gábor Gazdag 


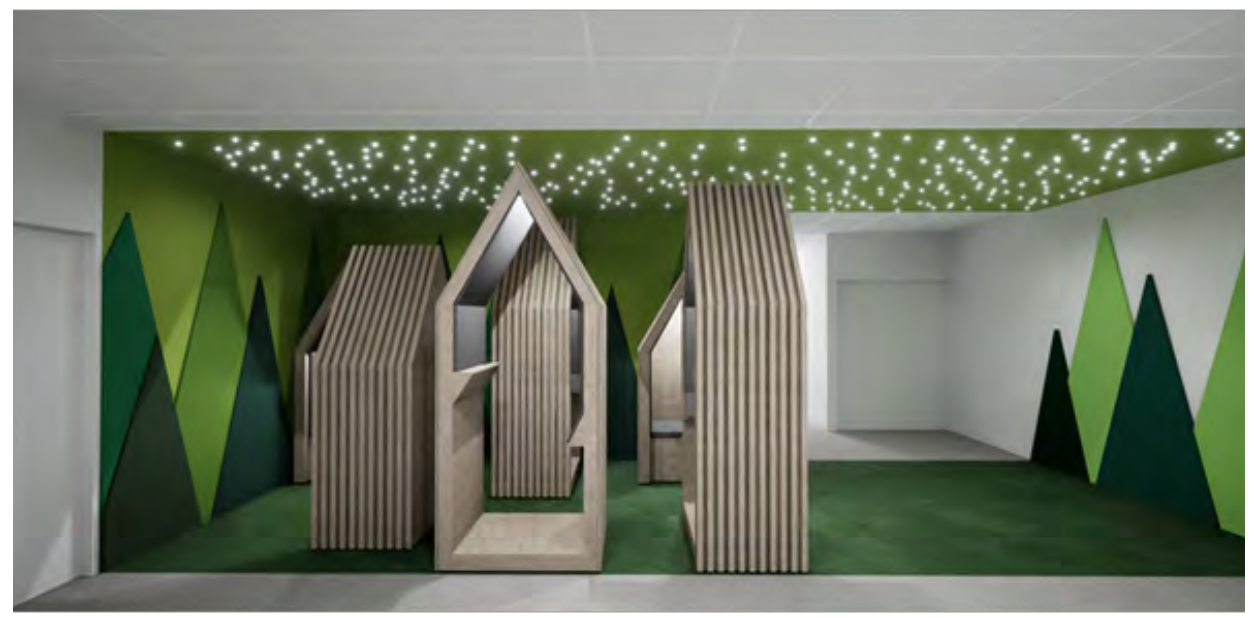

_ Figure 5: 3D visualization of the booth - Image authors: Gábor Gazdag and Attila Kovács

\section{The Snowy meadows - 5th floor - THE ICE CUBES}

Functions: focus room, private phone calls and private conversations

Size: 22 square meters

Snowy meadows and cold winters were the motives for designing this lounge. Hence, this space is composed with ice cubes floating inside. Employees can use each box or "cube" as they desire. For example, one can have a private call in one of the boxes, meanwhile another user can enjoy reading in another box. Alternatively, spontaneous meetings can take place according to their needs. This variety of activities can be placed because of the orientation and disposition of the boxes in this space.

The boxes were designed to provide the maximum level of comfort for the users. Each one is composed of soft seating areas (made by upholstery fabric sheets) and surrounded by tensile fabrics, which can adapt to the user's positions. These fabrics can help to absorb the sounds and noises that are produced inside the box.

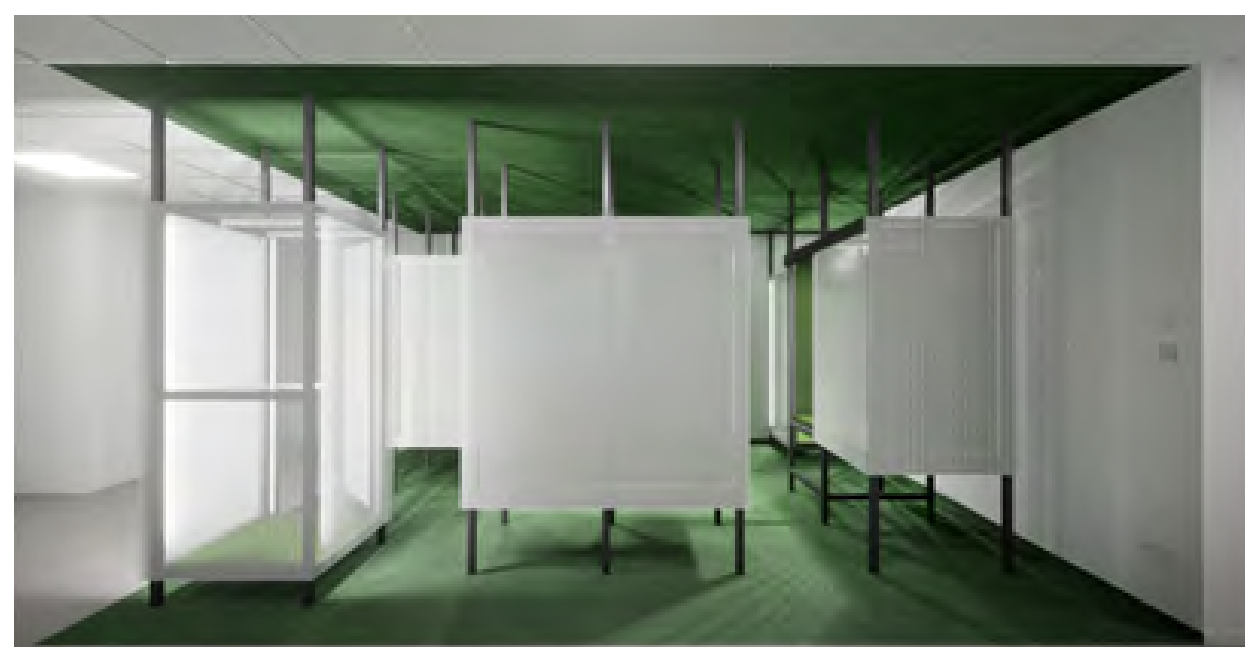

_ Figure 6 - Booths - Image authors: Pooya Noori and Attila Kovács 
In addition, the exteriors are constituted with translucent polycarbonate, which creates privacy, and at the same time a possibility to open the box and integrate it into the given space. In consequence, the skin gives the possibility to have a visual connection between the interior and exterior.

The load bearing structure is composed by hollow steel tubes. This solution creates the lightest possible structure and easier connections among the elements.

The lighting is provided with LED stripes located inside the boxes. Therefore, the boxes are illuminating as lanterns in the whole space, thus creating a magical atmosphere.

\section{Snowy fields - 6th floor - THE CREATIVE LOUNGE}

Functions: meeting room, relaxing space, innovation and technology room.

Size: 24.10 square meters.

The team got the inspiration regarding the design of the lounge on some snowy fields (as a theme of the floor) Consequently, the image of soft curves, meadows and snowy trees are represented in the concept.

In addition, the group remarked the particular conditions of the location considering the lounge. Having bright sunshine during afternoons and nice views towards the courtyard of the building. This peculiarity has motivated the group to choose this place for the creativity space.

The main idea of the group is to provide as much flexibility in the possible usage of the space as possible, according to the needs of the employees. For that reason, a rotating "wall" was designed, which will provide the integration of the whole space. It allows the users to scatter the furniture around the whole leisure area and enjoy the whole space. However, if the space is required for a meeting, the walls can be close it.

The organically shaped rotating walls can be used in different levels, thus encouraging relaxation and communication. Their structure is made of plywood and the upholstery is constructed of polyurethane foam.

The group also included hammock chairs hanging from the "trees branches" and the Tip Ton chair, which allows its users to swing within the space, hence changing the position in a playful way. The Tip Ton chair shows dual sitting postures that, according to studies from ETH Zurich in 2010, straightens the pelvis and spine and thus improves circulation in the abdominal and back muscles. The tree concept related to the nature of the fields, is presented in the design as a net of branches hanging from the ceiling where it helps to incorporate some suspended furniture and lighting as well.

\section{Lighting - smart lighting}

The lounge itself was planned to include the high technology gadgets which could be used by employees. For example, the walls have smart screens, which are connected with the organic shaped table and it is possible to link personal devices as well as mobile phones with them. Giving the users the smart flexibility as the technology can offer nowadays.

An automatic curtain system is also included in the project. The plan is to have three modes: manual mode, wireless remote control and automatic light sensor mode. As it is written below, one of the particularities of this lounge is strong light in the afternoon. Consequently, users can move the shades according to their needs. The shades can be operated with tablets, smartphones or a remote control.

\section{CONCLUTIONS}

It has proved that leisure spaces could contribute to the workers having better every day work experience [5].

According this paper office workplaces have a potential for improvement. The Research group took underused spaces and presented some projects considering employees' needs, examining data as well as the analysed literature $[1,2,4,6]$ for a better understanding of nowadays way of working. 
Having this office's style is possible because of the use of new technologies and the company's organization.

\section{REFERENCES}

- Magazine article: M. Apgar, (1998). The alternative workplace: Changing where and how people work. Harvard Business Review, 76(3), 121-136.

- Book chapter: D. Clements-Croome, 2006. "Creating the Productive Workplace: Consciousness, well-being and senses", edited by Derek Clements-Croome, Taylor \& Francis Group-2nd edition, 14-21. Abingdon: Milton Park.

- Blog entry or comment: Cort 2020. "Evolution of the Office" The Cort Blog, February 20. Accessed February 26, 2020. https://blog.cort.com/workplace/evolution-of-the-office-infographic/

_ Journal article: P. Fröst. 2016. "Administrative workplaces in healthcare: Designing an efficient and patient-focused environment." Journal of Hospital Administration, vol. 5, no. 4: 68-75.

- Journal article: M. Robertson, P. Vink. 2012. "Examining new ways of office work between the Netherlands and the USA." Journal Work, vol. 41, no. Supplement 1: 5086-5090.

- Book chapter. J. Rostron. 1996. "Sick Building Syndrome Concepts, issues and practice". In Overview of the possible causes of SBS and recommendations for improving the internal environment by A. J. Rayner, edited by J. Rostron. 5-29. Liverpool John Moores University. 